ARTICLE

\title{
Inter-element miscibility driven stabilization of ordered pseudo-binary alloy
}

\author{
Kenshi Matsumoto', Ryota Sato (10 1, Yasutomi Tatetsu (10 2 , Ryo Takahata', Seiji Yamazoe (i) ${ }^{3}$, \\ Miho Yamauchi (ib ${ }^{4}$, Yuji Inagaki (i) ${ }^{5}$, Yoichi Horibe ${ }^{6}$, Masaki Kudo ${ }^{7}$, Takaaki Toriyama7, Mitsunari Auchi ${ }^{7}$, \\ Mitsutaka Haruta (10 ${ }^{1}$, Hiroki Kurata ${ }^{1} \&$ Toshiharu Teranishi (iD ${ }^{1 凶}$
}

\begin{abstract}
An infinite number of crystal structures in a multicomponent alloy with a specific atomic ratio can be devised, although only thermodynamically-stable phases can be formed. Here, we experimentally show the first example of a layer-structured pseudo-binary alloy, theoretically called $Z 3-\mathrm{FePd}_{3}$. This $Z 3$ structure is achieved by adding a small amount of $\mathrm{In}$, which is immiscible with Fe but miscible with Pd and consists of an alternate $L 1_{0}$ (CuAu-type)-PdFePd trilayer and $\mathrm{Pd}-\mathrm{In}$ ordered alloy monolayer along the $\mathbf{c}$ axis. First-principles calculations strongly support that the specific inter-element miscibility of In atoms stabilizes the thermodynamically-unstable $Z 3-\mathrm{FePd}_{3}$ phase without significantly changing the original density of states of the $Z 3-\mathrm{FePd}_{3}$ phase. Our results demonstrate that the specific interelement miscibility can switch stable structures and manipulate the material nature with a slight composition change.
\end{abstract}

\footnotetext{
${ }^{1}$ Institute for Chemical Research, Kyoto University, Gokasho, Uji, Kyoto 611-0011, Japan. ${ }^{2}$ Center for Liberal Arts Education, Meio University, Biimata, Nago, Okinawa 905-8585, Japan. ${ }^{3}$ Department of Chemistry, Graduate School of Science, Tokyo Metropolitan University, 1-1 Minami-Osawa, Hachioji, Tokyo 1920397, Japan. ${ }^{4}$ Institute for Materials Chemistry and Engineering (IMCE), Kyushu University, 744 Motooka, Nishi-ku, Fukuoka 819-0395, Japan.

${ }^{5}$ Department of Applied Quantum Physics and Nuclear Engineering, Faculty of Engineering, Kyushu University, 744 Motooka, Nishi-ku, Fukuoka 819-0395, Japan. ${ }^{6}$ Department of Materials Science and Engineering, Graduate School of Engineering, Kyushu Institute of Technology, 1-1 Sensui, Tobata, Kitakyuushu, Fukuoka 804-8550, Japan. ${ }^{7}$ The Ultramicroscopy Research Center, Kyushu University, 744 Motooka, Nishi-ku, Fukuoka 819-0395, Japan.

凶email: teranisi@scl.kyoto-u.ac.jp
} 
T he crystal structure is a crucial factor for determining the physical and chemical properties because the atomic arrangement dominates the atomic-orbital hybridization ${ }^{1-5}$. In a multicomponent alloy system, even with a specific atomic ratio, a number of geometrically available crystal structures can be devised ${ }^{6,7}$. Although this geometrical possibility means that there is still room to investigate crystal-structure control to realize a fine or drastic tuning of material properties, only thermodynamically stable phases at low and high temperatures have been commonly formed which follow the phase diagrams ${ }^{8}$, except for the recently reported cases under extreme conditions, such as size $e^{9}$, pressure ${ }^{10}$, and lattice $\operatorname{strain}^{11}$. For instance, in the case of the $\mathrm{FePd}_{3}$ alloy system targeted in this research, only the thermodynamically stable $L_{2} \quad\left(\mathrm{Cu}_{3} \mathrm{Au}\right.$-type) phase has been experimentally obtained ${ }^{5,7,8}$. Therefore, a synthetic strategy of stabilizing a crystal structure is deserved.

To create an ordered alloy with such an atomic arrangement as the layered structures shown in Supplementary Fig. 1, we paid attention to the inter-element miscibility-the miscibility between two elements at an atomic level-in a binary-alloy phase diagram ${ }^{8}$. Recently, the transformation from $A 1-$ to $L 1_{0}-\mathrm{FeNi}$ structures was achieved by introducing and withdrawing interstitial $\mathrm{N}$ atoms ${ }^{12}$. The $\mathrm{Fe}-\mathrm{Ni}-\mathrm{N}$ compound formed during this process possessed a crystal structure with a unit cell composed of one $\mathrm{Fe}-\mathrm{N}$ layer sandwiched by two Ni layers in such a way as to reflect the better binding affinity of Fe with $\mathrm{N}$, such as $\mathrm{N}_{2}$ dissociation by Fe catalyst ${ }^{13}$. This structural transformation caused by the interelement affinity of an interstitial $\mathrm{N}$ with $\mathrm{Fe}$ and $\mathrm{Ni}$ inspired us to analogically consider that the transformation from well-known to unexplored structures of a binary alloy could be achieved by the difference in the miscibility of a substitutional third element with the two kinds of elements in binary alloys.

To demonstrate this idea, we focused on the binary alloy of Pd and $\mathrm{Fe}$, because many third elements can be miscible with Pd and immiscible with $\mathrm{Fe}$ in the binary phase diagram ${ }^{8}$. The element In was selected as a substitutional third element. Between the wellknown $L 1_{2}-\mathrm{FePd}_{3}$ and $L 1_{0}-\mathrm{FePd}$ phases in the $\mathrm{Fe}-\mathrm{Pd}$ system, we chose the $L_{2}-\mathrm{FePd}_{3}$ as a target crystal phase because of its likeliness to change crystal structure from an isotropic $L 1_{2}$ structure to a highly anisotropic structure when selectively locating the In atoms at specific sites. Such a structural change would, in turn, alter the physical properties. However, according to previous reports, Fe-Pd-In ternary alloys have been rarely reported except for the In-rich ternary alloys $(\mathrm{In} /(\mathrm{Fe}+\mathrm{Pd}+\mathrm{In})>20$ atomic percent (at.\%) $)^{14,15}$ and the In-poor $L 1_{2}$-type $\mathrm{FePd}_{3}$ ternary alloy phases $(\mathrm{In} /(\mathrm{Fe}+\mathrm{Pd}+\mathrm{In})<1.2 \text { at. } \%)^{16}$. This indicates the difficulty in producing other Fe-Pd-In ternary alloys with a small amount of In composition (e.g., $1.2<\mathrm{In} /(\mathrm{Fe}+\mathrm{Pd}+\mathrm{In})<20$ at.\%).

In this work, we create the $\mathrm{Fe}-\mathrm{Pd}$-In ternary alloy phase $(11<\operatorname{In} /(\mathrm{Fe}+\mathrm{Pd}+\mathrm{In})<14$ at.\%) with a Z3-based structure by using nanoparticulate precursor powders, because the uniformly mixing of $\mathrm{Fe}, \mathrm{Pd}$, and In at the nanoscale is crucial for the formation of Z3-type structure. Experimental results and firstprinciples calculation show that the stabilization of $Z 3-\mathrm{Fe}(\mathrm{P}-$ $\left.\mathrm{d}, \mathrm{In}^{d}\right)_{3}$ is induced by not a nanosize or a kinetic effect but a specific inter-element miscibility of In, which is miscible with Pd but immiscible with Fe. This idea that the inter-element miscibility of the third element works as a stabilizer of an ordered structure gives us an opportunity for the experimental discovery of a variety of novel ordered structures.

\section{Results}

Creation of layer-structured Fe-Pd-In alloy nanoparticles. Fe-Pd alloy nanoparticles (NPs) containing a small amount of In atoms were synthesized by a step-by-step chemical synthesis (Supplementary Table 1); (i) synthesis of 23-nm Pd NPs (Fig. 1a) ${ }^{17}$, (ii) alloying of In with Pd NPs to form $A 1-P d I_{x}$ NPs (Fig. 1b), (iii) growth of $\mathrm{FeO}_{y}$ shells on $A 1-\mathrm{PdIn}_{x} \mathrm{NPs}$ (Fig. 1c) $)^{17,18}$ and (iv) diffusion of Fe atoms into $A 1-\mathrm{PdIn}_{x} \mathrm{NPs}$ through the reductive annealing of $\mathrm{FeO}_{y}$ shells at $600^{\circ} \mathrm{C}$ or $800^{\circ} \mathrm{C}$ for $3 \mathrm{~h}$ under a $4 \% \mathrm{H}_{2}$ gas flow (Ar balance) (Fig. 1d). First, we analysed the NPs with the $\mathrm{Pd} / \mathrm{In} / \mathrm{Fe}$ atomic ratio of $63 / 14 / 23(\mathrm{Pd} /$ In $=82 / 18$ at. $\%$ and $\mathrm{Pd} / \mathrm{Fe}=73 / 27$ at.\%), which was confirmed by energy-dispersive X-ray spectrometry (EDX). Figure 1e-g show Rietveld refinement for the powder X-ray diffraction (XRD) patterns and the high-angle annular dark-field scanning transmission electron microscopy (HAADF-STEM) image of the final NPs. These NPs could not be assigned to any structures in the Fe $-\mathrm{Pd}$ and $\mathrm{Pd}-\mathrm{In}$ systems $^{8}$, but it was found that they had the P4/ $m m m$ structure with the atomic coordinates of $\mathrm{Fe}^{1 a}(0,0,0), \mathrm{Fe}^{1 c}$ $(0.5,0.5,0), \mathrm{Pd}^{4 i}(0.5,0,0.23), \mathrm{Pd}^{1 b}(0,0,0.5)$, and $\mathrm{Pd}^{1 d}(0.5,0.5$, $0.5)$ in the unit cell, where the superscripts refer to the multiplicities and Wyckoff letters. Therefore, the NPs had a
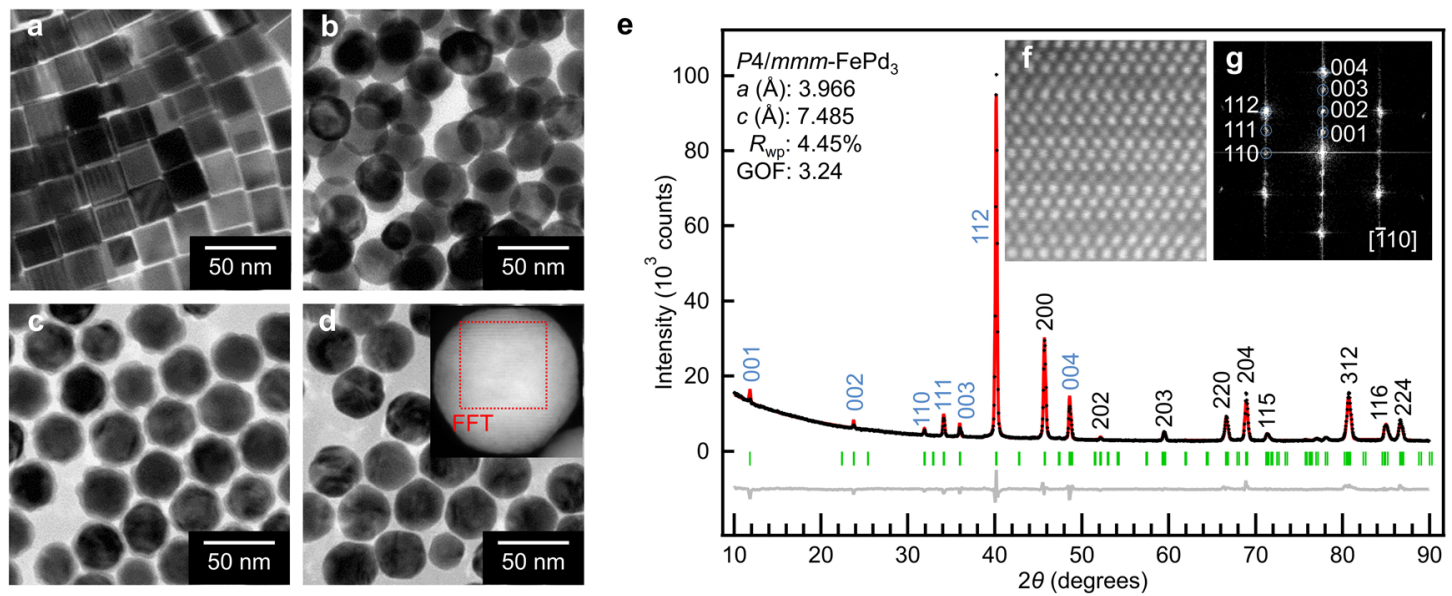

Fig. 1 Synthesis and characterization of monodisperse Fe-Pd alloy NPs with a small amount of In. a-d, TEM images of 23-nm Pd NPs (a), A1-PdIn $n_{x}$ S with $\mathrm{Pd} / \mathrm{In}=82 / 18$ at.\% (b), A1-PdIn $@ @ \mathrm{FeO}_{y}$ core@shell NPs with Pd/Fe = 73/27 at.\% (c) and the NPs obtained by the reductive annealing of $\mathbf{c}$ at $600{ }^{\circ} \mathrm{C}$ for $3 \mathrm{~h}$ (d) (the inset shows the HAADF-STEM image of $\mathbf{d}$ ). e, Rietveld refinement for powder XRD patterns of the NPs obtained by the reductive annealing of $\mathbf{c}$ at $800^{\circ} \mathrm{C}$ for $3 \mathrm{~h}$, where the black markers are raw data, the red is the fitting curve, the gray line is a difference curve of raw data and the fitting curve, and the green bars stand for the whole diffraction-peak positions. $R_{\mathrm{wp}}$ and GOF are a reliability factor and a goodness of fit, respectively. $\mathbf{f}, \mathbf{g}$. Magnified HAADF-STEM image (f) and the fast Fourier transform (FFT) image (g) of the inset in $\mathbf{d}$ 


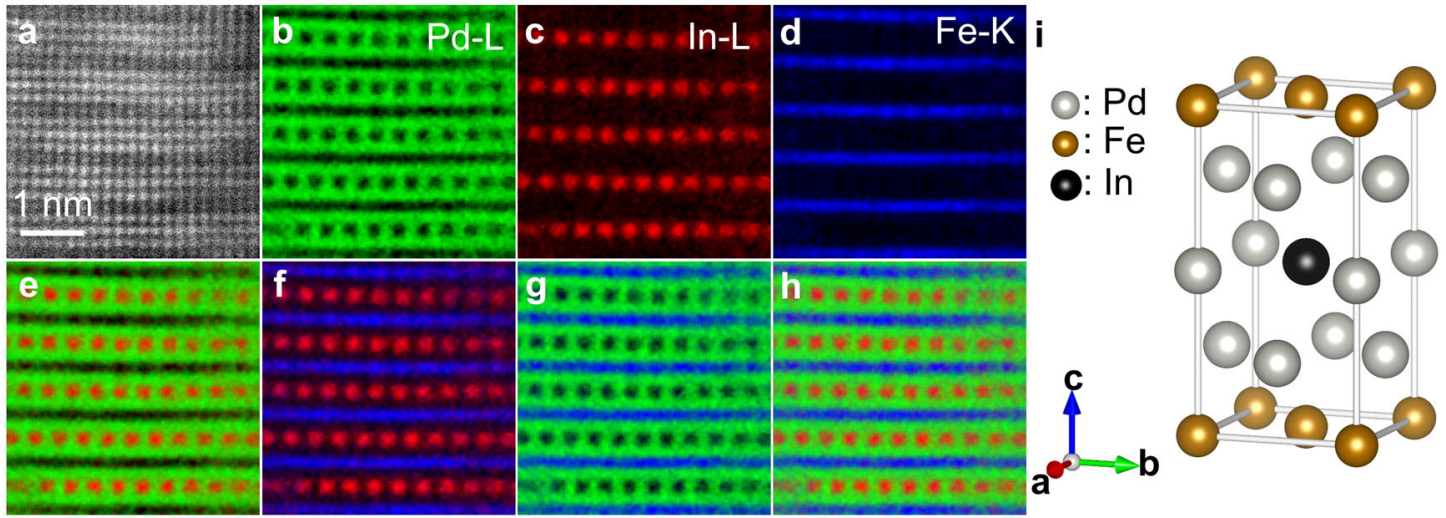

Fig. 2 Direct observation of In atoms in Z3-type structure. a-d, HAADF-STEM image (a) and the elemental maps (Pd-L (b), In-L (c) and Fe-K (d)) of Z3-type structure. e-h, Overlay of $\mathbf{b}$ and $\mathbf{c}(\mathbf{e}), \mathbf{c}$ and $\mathbf{d}(\mathbf{f}), \mathbf{b}$ and $\mathbf{d}(\mathbf{g})$, and $\mathbf{b}-\mathbf{d}(\mathbf{h})$. i, Unit cell of Z3-Fe(Pd,Ind) ${ }_{3}$ determined from Fig. 1e-g and Fig. 2a-h.

superlattice structure with an alternate stacking of a single Featomic layer and three Pd-atomic layers along the $\mathbf{c}$ axis (Fig. 1e-g), which is called the $Z 3-\mathrm{FePd}_{3}{ }^{6,7,19}$. However, it was quite difficult to detect the In atoms from the intensity ratio of the XRD peaks and the $Z$ contrast of the HAADF-STEM image, because the electron density of In is very close to that of Pd. To identify the In sites in the $Z 3$ framework, we performed elemental mapping by EDX at the atomic resolution. As a result, In atoms were found to be selectively excluded from both the $\mathrm{Fe}$ and In atoms and preferentially occupied the $1 d$ or $1 b$ site, which corresponded to the middle Pd layer among the three Pd layers (Fig. 2a-e). Consequently, the resulting Z3 structure with the In atoms at the $1 d$ site was precisely denoted to be $Z 3-\mathrm{Fe}\left(\mathrm{Pd}, \mathrm{In}^{d}\right)_{3}$.

Dependence of Fe-Pd-In alloy phase on In quantity. Next, to investigate the In composition inducing the formation of the Z3-type structure, the Pd-In@FeO $y$ core@shell NPs $(\mathrm{Pd} / \mathrm{Fe} \approx 70$ / 30 at.\%) were annealed at $800^{\circ} \mathrm{C}$ for $3 \mathrm{~h}$ (Supplementary Table 1). Powder XRD patterns verified that the reductive annealing for Pd-In@FeO ${ }_{y}$ core@shell NPs with the Pd/In of 89/11 at.\%, 85/15 and $83 / 17$ at. $\%$, and $73 / 27$ at.\% gave the $L 1_{2}$-type phase, the $Z 3$-type phases and a mixture of all three phases $\left(A 1-\mathrm{Fe}_{60} \mathrm{Pd}_{40}\right.$, Pnma-PdIn ${ }_{2}$, and $I 4 / \mathrm{mmm}$ phases), respectively (Supplementary Fig. 2). This indicated that the Z3-type structure can be formed in a narrow range of In compositions.

To further confirm the In sites in not only the Z3-type but also the $L 1_{2}$-type structures, we performed the X-ray absorption fine structure (XAFS) measurement for these structures at the Fe-, Pdand In-K edges. The In environment determined from the extended XAFS (EXAFS) regions at the In-K edge revealed that the In atoms in the $L 1_{2}$-type and $Z 3$-type structures were surrounded only by approximately $12 \mathrm{Pd}$ atoms, that is, $L 1_{2}$ $(\mathrm{Fe}, \mathrm{In}) \mathrm{Pd}_{3}$ and $\mathrm{Z3}-\mathrm{Fe}\left(\mathrm{Pd}, \mathrm{In}^{d}\right)_{3}$ were formed by partially replacing $\mathrm{Fe}$ and $\mathrm{Pd}(1 d$ site) far from the $\mathrm{Fe}$ with In, respectively (Supplementary Fig. 3 and Table 2). This tendency strongly implied that the inter-element miscibility of In with other elements, that is, immiscible with $\mathrm{Fe}$ and miscible with $\mathrm{Pd}$, dominated the In sites.

Investigation of driving force for stabilizing Z3-type structure. Although we found that the formation of Z3-type structure depends on the In composition, the driving force for stabilizing Z3-type structure is yet to be clarified. Besides the thermodynamic effect, the kinetic and/or the nano-size effects 9 should be considered as the candidates of the driving force for forming Z3-type structure. First, to investigate whether Z3-type structure was a kinetically or a thermodynamically stable phase below $800^{\circ} \mathrm{C}$, we conducted in situ XRD measurement for A1-PdIn $@ \mathrm{FeO}_{y} @ \mathrm{SiO}_{2}$ nanoparticles under the reductive annealing at $800^{\circ} \mathrm{C}\left(\mathrm{SiO}_{2}\right.$ was coated on A1-PdIn $@ \mathrm{FeO}_{y}$ nanoparticles to avoid the interparticle fusion). As a result, only Z3-type phase was formed by the reductive annealing at $800^{\circ} \mathrm{C}$ for $4 \mathrm{~min}$ and further annealing at $800^{\circ} \mathrm{C}$ for $25 \mathrm{~h}$ did not change the crystal phase (Supplementary Fig. 4). Therefore, we concluded that the $Z 3$-type structure was a thermodynamically stable phase below $800^{\circ} \mathrm{C}$.

Next, to investigate whether a particle size contributes to stabilizing the Z3-type structure, we synthesized micrometer-scale $\mathrm{Fe}-\mathrm{Pd}-\mathrm{In}$ ternary alloy particles via the interparticle sintering of $\mathrm{PdIn} @ \mathrm{FeO}_{y}$ nanoparticles by the reductive annealing at $800{ }^{\circ} \mathrm{C}$ for $3 \mathrm{~h}$, which gave the Z3-type structure (Supplementary Fig. 5). On the other hand, when the reductive annealing was conducted for a mixture of $\mathrm{Pd} @ \mathrm{FeO}_{y} \mathrm{NPs}(\mathrm{Pd} / \mathrm{Fe}=74 / 26$ at.\%) and In powder $(\mathrm{Pd} / \mathrm{In}=82 / 18$ at.\%), in which In was inhomogeneously distributed, at $800{ }^{\circ} \mathrm{C}$ for $3 \mathrm{~h}$, the Z3-type structure did not form (Supplementary Fig. 6). These results strongly support that the nanoparticulate precursor powders composed of homogeneously mixed $\mathrm{Fe}, \mathrm{Pd}$, and $\mathrm{In}$ at the nanoscale are crucial for the formation of Z3-type structure even if the Z3-type structure is not stable specifically at the nanoscale ${ }^{9}$.

To determine why the $Z 3-\mathrm{Fe}\left(\mathrm{Pd}, \mathrm{In}^{d}\right)_{3}$ structure was preferentially formed, we undertook a theoretical approach using firstprinciples calculations. First, we calculated the formation energies $\left(E_{\text {form }}\right)$ of various $\mathrm{FePd}_{3}$ phases in $L 1_{2}$ and $Z 3$ structures before and after adding In by using the equation below;

$$
E_{\text {form }}=E\left[\mathrm{Fe}_{x} \mathrm{Pd}_{y} \operatorname{In}_{z}\right]-(x \times \mu[\mathrm{Fe}]+y \times \mu[\mathrm{Pd}]+z \times \mu[\mathrm{In}])
$$

where $E\left[\mathrm{Fe}_{x} \mathrm{Pd}_{y} \operatorname{In}_{z}\right]$ represents the total energies of $Z 3$ - or $L 1_{2}$ $\mathrm{Fe}_{x} \operatorname{Pd}_{y} \operatorname{In}_{z}((x, y, z)=(2,6,0),(2,5,1)$, or $(1,6,1))$ and $\mu[\mathrm{Fe}]$, $\mu[\mathrm{Pd}]$ and $\mu[\mathrm{In}]$ are the chemical potentials of $\mathrm{Fe}, \mathrm{Pd}$ and In, respectively, which are equivalent to their total energies of the ground states. As shown in Fig. 3a, the calculation results showed that the $L 1_{2}-\left(\mathrm{Fe}_{1}, \mathrm{In}_{1}\right) \mathrm{Pd}_{6}$ and $Z 3-\mathrm{Fe}_{2}\left(\mathrm{Pd}_{5}, \mathrm{In}_{1}{ }^{d}\right)$ structures were most stable in each structural type, which was in good agreement with the In sites in $L 1_{2}$-type and $Z 3$-type structures estimated from XAFS analysis. Furthermore, the differences in $E_{\text {form }}$ values between $L 1_{2}-\left(\mathrm{Fe}_{2-x}, \mathrm{In}_{x}\right) \mathrm{Pd}_{6}$ and $Z 3-\mathrm{Fe}_{2}\left(\mathrm{Pd}_{6-x}, \mathrm{In}_{x}{ }^{d}\right)(0<x<1)$ (see Methods) showed that the Z3-type structure became more stable than the $L 1_{2}$-type structure from $x>0.48$, or $\mathrm{In} /(\mathrm{In}+\mathrm{Pd})>8$ at. $\%$ (Fig. 3b). The calculation results also agreed with the experimental tendency in terms of the phase transition and the critical In/Pd at.\% from the $L 1_{2}$-type to $Z 3$-type phases when increasing the In composition. Therefore, although the $\mathrm{L1}_{2}-\mathrm{FePd}_{3}$ structure is thermodynamically stable for $\mathrm{FePd}_{3}$ systems ${ }^{5,7,8}$, introducing a 


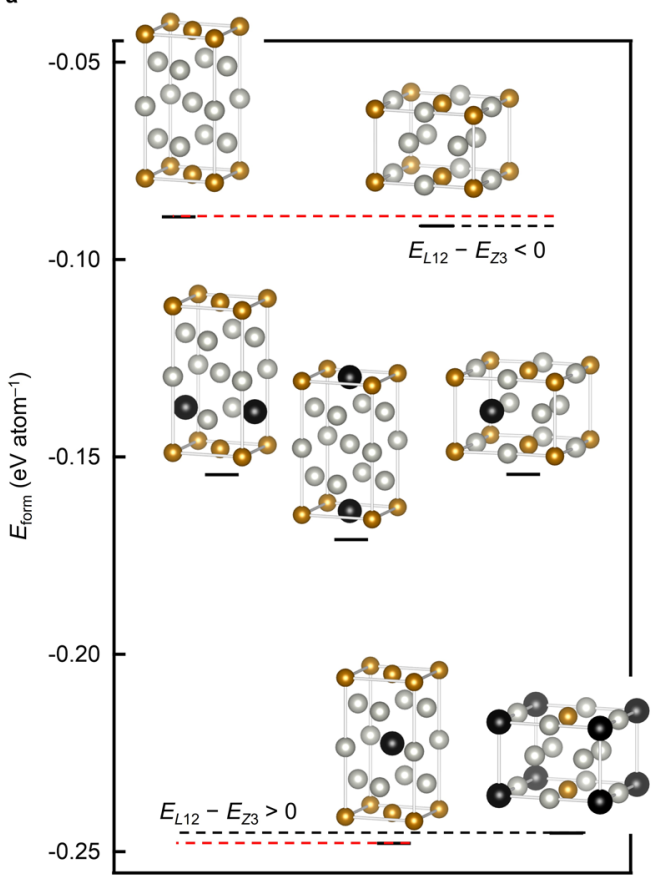

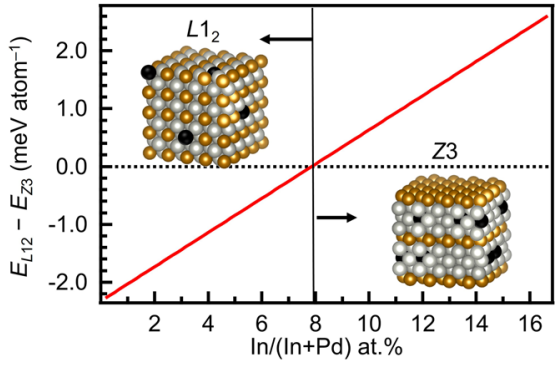

c

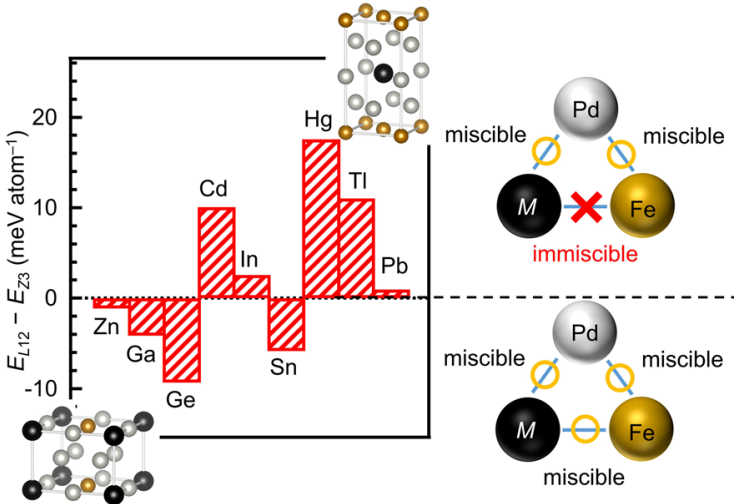

Fig. 3 Formation energies of Z3-type versus $\mathbf{L 1}_{\mathbf{2}}$-type structures. a Formation energies of $Z 3$-type and $L 1_{2}$-type phases $\left(E_{\text {form }}\right)$ with $I n$ atoms in different sites. $\mathbf{b}$, In composition-dependent formation energy difference between $Z 3-F_{2}\left(P d_{6-x}, \ln _{x}{ }^{d}\right)$ and $L 1_{2}-\left(F_{2-x}, \ln _{x}\right) P d_{6}(0 \leq x \leq 1)\left(E_{Z 3}\right.$ and $E_{L 12}$, respectively) phases, where 16.67 of $\mathrm{In} /(\mathrm{In}+\mathrm{Pd})$ at.\% corresponds to $x=1$. c, Formation energies of most stable $Z 3-\mathrm{Fe}_{2}\left(\mathrm{Pd}_{5}, M_{1}{ }^{d}\right)$ versus most stable $L 1_{2}-\left(\mathrm{Fe}_{1}, M_{1}\right) P \mathrm{P}_{6}$ in each crystal structure with the 12-14 groups additional-metallic element $(M)$. Only when adding the elements $M$ immiscible with Fe, was the Z3-type structure more stable than the $L 1_{2}$-type structure.

small amount of In atoms into $\mathrm{FePd}_{3}$ systems makes the Z3-type structure more stable than the $L 1_{2}$-type structure.

The In sites shown in the experimental and theoretical data were likely to reflect the inter-element miscibility of In with $\mathrm{Fe}$ and Pd. To investigate whether the inter-element miscibility of In contributed to the stabilization of Z3-type phase, we conducted the same first-principles calculations for the nine 12-14 groups elements $(M=\mathrm{Zn}, \mathrm{Cd}, \mathrm{Hg}, \mathrm{Ga}, \mathrm{In}, \mathrm{Tl}, \mathrm{Ge}, \mathrm{Sn}$, and $\mathrm{Pb})$ in the periodic table as that used for In. Very interestingly, the Z3-type structure was more stable than the $L 1_{2}$-type structure when introducing $\mathrm{Cd}, \mathrm{Hg}$, In, $\mathrm{Tl}$ and $\mathrm{Pb}$ which possessed the same miscibility as In with $\mathrm{Fe}$ and $\mathrm{Pd}^{8,20}$. On the other hand, the Z3-type structure remained unstable when adding $\mathrm{Zn}, \mathrm{Ga}, \mathrm{Ge}$, and $\mathrm{Sn}$ which are miscible with $\mathrm{Fe}$ and $\mathrm{Pd}^{8}$ (Fig. 3C). Since these calculations do not consider other candidates except for isotropic $L 1_{2}$-type and anisotropic $Z 3$-type phases, one should note the differences in these formation energies at this composition, however, in the $\mathrm{Fe}-\mathrm{Pd}-\mathrm{Pb}$ system, the formation of Z3$\mathrm{Fe}\left(\mathrm{Pd}_{2.5}, \mathrm{~Pb}_{0.5}{ }^{d}\right)$ structure was confirmed by the similar step-bystep chemical synthesis as the synthetic process inducing Z3$\mathrm{Fe}\left(\mathrm{Pd}, \mathrm{In}^{d}\right)_{3}$ structure (see Methods and Supplementary Fig. 7). These results strongly support our claim that a third element selected by specific inter-element miscibility possess the potential to stabilize a binary alloy like the $Z 3$ structure.

Physical properties of $Z \mathbf{Z 3}-\mathrm{Fe}\left(\mathbf{P d}, \mathrm{In}^{d}\right)_{3}$ structure. Finally, we investigated the novel physical properties characteristic of the Z3-type structure. First, the Z3-type structure was expected to show high coercivity because of having a $L 1_{0}$-type PdFePd trilayer $^{17,21,22}$. Magnetization-magnetic field $(M-H)$ curves were measured for the $L 1_{2}$ - $(\mathrm{Fe}, \mathrm{In}) \mathrm{Pd}_{3}$ and $Z 3-\mathrm{Fe}\left(\mathrm{Pd}, \mathrm{In}^{d}\right)_{3} \mathrm{NPs}(\mathrm{Pd} / \mathrm{Fe}$ $\approx 70 / 30$ at.\%) synthesized by annealing at $600{ }^{\circ} \mathrm{C}$ for $3 \mathrm{~h}$ with the $\mathrm{Pd} / \mathrm{In}$ at.\% of $89 / 11$ and $83 / 17$, respectively, at room temperature

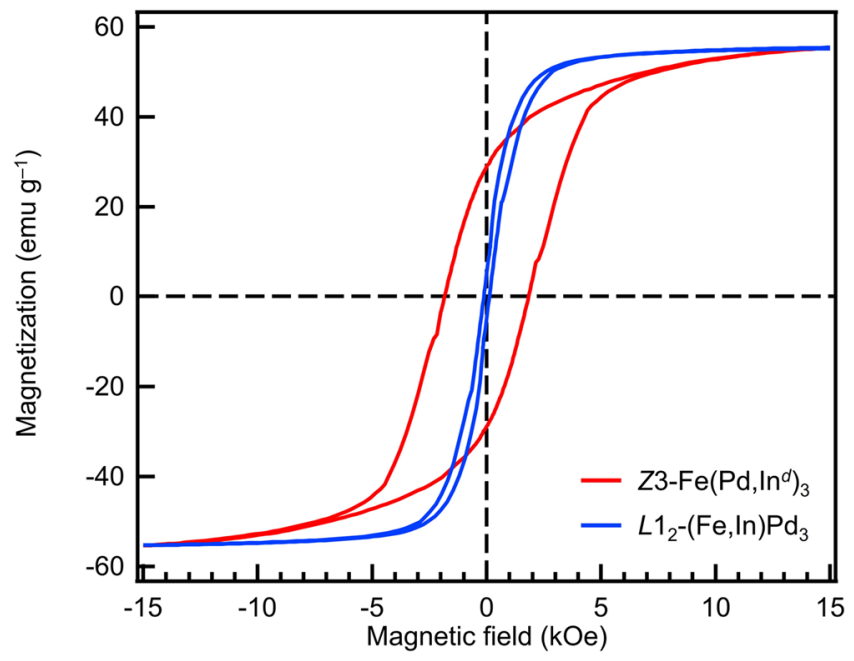

Fig. 4 Magnetic properties of $\mathbf{L 1}_{\mathbf{2}}-(\mathbf{F e}, \mathbf{I n}) \mathbf{P d}_{\mathbf{3}}$ and $\mathbf{Z 3}-\mathbf{F e}\left(\mathbf{P d}, \operatorname{In}^{d}\right)_{\mathbf{3}} \mathbf{N P s}$. $M-H$ hysteresis loop of Z3-type NPs (Pd/In = 83/17 at.\%) and $L 1_{2}$-type NPs $(\mathrm{Pd} / \mathrm{In}=89 / 11$ at.\%) measured by VSM at room temperature.

by means of a vibrating sample magnetometer (VSM). Both the $L 1_{2}$-type and $Z 3$-type NPs showed a ferromagnetic feature with almost the same saturation magnetization, while the Z3-type NPs possessed a coercivity that was 15 times higher than the $L 1_{2}$-type NPs and behaved as a magnetically hard phase similar to the $L 1_{0}$ $\mathrm{NPs}^{21,22}$ (Fig. 4). This coercivity enhancement could be explained by the drastic increase in the magnetic anisotropy energy ${ }^{23}$ induced by the crystal structure change from $L 1_{2}$ to $Z 3$ frameworks $\left(-1.38 \mu \mathrm{eV}\right.$ atom ${ }^{-1}$ for $L 1_{2}$-type structure and $-0.213 \mathrm{meV}$ atom $^{-1}$ for Z3-type structure (see Methods)). 
As another structure-specific physical property, the Z3-type structure is also likely to possess a hydrogen-storage ability, owing to one Pd-In ordered alloy layer sandwiched by two Pd layers similar to the Pd-rich alloy structure ${ }^{24}$. However, it was found from the pressure-composition isotherms at $30^{\circ} \mathrm{C}$ and $60^{\circ} \mathrm{C}$ that this $Z 3$-type structure had no hydrogen-storage ability (Supplementary Fig. 8). This hydrogen-storage ability can be understood by the small amount of $4 d$ hole of Pd in the Z3-type structure shown by the density of states (DOS), which are obtained from first-principles calculations (Supplementary Fig. 9 $)^{25}$. The DOS feature also showed no significant difference in the DOS near the Fermi level and the $d$-bandwidths and centers of $\mathrm{Fe}$ and Pd between the $Z 3-\mathrm{Fe}_{2}\left(\mathrm{Pd}_{5}, \mathrm{In}_{1}{ }^{d}\right)$ and $Z 3-\mathrm{Fe}_{2} \mathrm{Pd}_{6}$ structures. No significant change in DOS of $Z 3-\mathrm{Fe}_{2}\left(\mathrm{Pd}_{5}, \mathrm{In}_{1}{ }^{d}\right)$ and $Z 3-\mathrm{Fe}_{2} \mathrm{Pd}_{6}$ structures indicates that the physical properties characteristic of the $Z 3-\mathrm{FePd}_{3}$ structure are still observed even if a small amount of In atoms are introduced into the $Z 3-\mathrm{FePd}_{3}$ framework.

\section{Discussion}

We proposed the concept that the inter-element miscibility stabilizes a binary alloy with an ordered structure. As an example, we demonstrated that introducing a small amount of In atoms enabled the formation of $Z 3-\mathrm{Fe}\left(\mathrm{Pd}, \mathrm{In}^{d}\right)_{3}$ NPs with an almost identical DOS as the $Z 3-\mathrm{FePd}_{3}$ structure, where the synthetic procedure using the nanoparticulate precursor powders such as $A 1-\mathrm{PdIn}_{x} @ \mathrm{FeO}_{y} \mathrm{NPs}$ were crucial for creating the Z3-type structure. These results indicate that ordered alloy structures can be experimentally discovered according to the binary-phase diagrams $s^{8,20}$ rather than searching for synthesizable structures using first-principles calculations ${ }^{26,27}$. We expect that a variety of ordered alloy nanostructures will be discovered that exhibit unexpected and excellent properties.

\section{Methods}

Materials. All reagents and solvents were commercially available. Sodium tetrachloropalladate(II) $\left(\mathrm{Na}_{2} \mathrm{PdCl}_{4}, 98 \%\right)$, polyvinylpyrrolidone (PVP, $\left.M_{\mathrm{w}} \approx 55,000\right)$, ascorbic acid (AA, $99+\%)$, potassium bromide $(\mathrm{KBr}, \geq 99 \%)$, oleylamine (OAm, $80-90 \%)$, 1-octadecene (ODE, $90 \%$ ), indium(III) chloride $\left(\mathrm{InCl}_{3}, 98 \%\right)$, indium powder (In, >99.99\%), eicosane (99\%), ammonium hydrogen solution $\left(\mathrm{NH}_{3} \mathrm{aq}\right.$, $28-30 \%$ ), tetraethyl orthosilicate (TEOS, 98\%) and polyoxyethylene nonylphenylether (IGEPAL@CO-520, $M_{\mathrm{w}}=441$ ) were purchased from Sigma-Aldrich. Iron pentacarbonyl $\left(\mathrm{Fe}(\mathrm{CO})_{5}, 95 \%\right)$ was purchased from Kanto Chemical Corporation. Oleic acid $(\mathrm{OA},>85 \%)$ was purchased from Tokyo Chemical Industry. Lead (II) acetate trihydrate $\left(\mathrm{Pb}(\mathrm{OAc})_{2} \cdot 3 \mathrm{H}_{2} \mathrm{O}\right)$, ethanol, acetone, $n$-hexane, chloroform, and cyclohexane were purchased from Wako Pure Chemical Industries. Boron nitride (BN, > 99.5\%) powder was purchased from Nacalai Tesque. Chemical reagents were used as received without further purification except for the synthetic process of $\mathrm{Pd}-\mathrm{Pb} @ \mathrm{FeO}_{y} \mathrm{NPs}$.

Synthesis of Pd NPs. Pd NPs were synthesized by the previously reported procedure ${ }^{17}$. After the rapid injection of an aqueous solution $(30 \mathrm{~mL})$ of $\mathrm{Na}_{2} \mathrm{PdCl}_{4}$ $(1.5 \mathrm{~g})$ and $\mathrm{KBr}(8.0 \mathrm{~g})$ into an aqueous solution $(270 \mathrm{~mL})$ of PVP $(2.8 \mathrm{~g})$ and AA $(0.66 \mathrm{~g})$, the reaction solution was kept at $80^{\circ} \mathrm{C}$ for $3 \mathrm{~h}$ and then cooled to room temperature. The above black solution of $\mathrm{Pd}$ seeds $(15 \mathrm{~mL})$ was injected into an aqueous solution $(250 \mathrm{~mL})$ of $\mathrm{Na}_{2} \mathrm{PdCl}_{4}(1.5 \mathrm{~g})$ and $\mathrm{KBr}(3.0 \mathrm{~g})$ at $40{ }^{\circ} \mathrm{C}$ and then an aqueous solution $(25 \mathrm{~mL})$ of PVP $(2.8 \mathrm{~g})$ and an aqueous solution $(25 \mathrm{~mL})$ of AA $(1.8 \mathrm{~g})$ were injected every $30 \mathrm{~min}$ at $40^{\circ} \mathrm{C}$. This solution was kept at $40^{\circ} \mathrm{C}$ for $48 \mathrm{~h}$, heated from $40^{\circ} \mathrm{C}$ to $60^{\circ} \mathrm{C}$ and kept at $60^{\circ} \mathrm{C}$ for $48 \mathrm{~h}$. Finally, the reaction solution was cooled to room temperature and the Pd NPs with an average edge length of $23 \mathrm{~nm}$ were collected by centrifugation with acetone and then purified with an ethanol/acetone (1/4 vol.\%) mixed solvent.

Synthesis of Pd-In alloy NPs. To react the Pd NPs with the In precursor in an organic solution, the surface ligand passivating the Pd NPs was exchanged from PVP to OAm by heating a mixture of OAm $(10 \mathrm{~mL})$, chloroform $(20 \mathrm{~mL})$ and $\mathrm{Pd}$ NPs $(0.5 \mathrm{mmol})$ at $50^{\circ} \mathrm{C}$ for $30 \mathrm{~min}$. The solution was cooled to room temperature and the OAm-protected Pd NPs were collected by centrifugation with ethanol and purified twice with a chloroform/ethanol (2/3 vol.\%) mixed solvent. After the ligand exchange, the OAm-protected Pd NPs were stirred with the mixture of $\mathrm{InCl}_{3}$ $\left(n_{\text {In }} \mathrm{mmol}\right)$, OAm $(32 \mathrm{~mL})$ and OA $(3.3 \mathrm{~mL})$ at $T^{\circ} \mathrm{C}$ for $3 \mathrm{~h}$ (Supplementary Table 1). Then, the organic solution was cooled to room temperature and the
Pd-In alloy NPs were collected by centrifugation with ethanol and purified twice with a chloroform/ethanol (3/5 vol.\%) mixed solvent.

Synthesis of Pd-In@FeO $\mathbf{y}_{\boldsymbol{y}}$ NPs. The $\mathrm{FeO}_{y}$ shells were grown on the Pd-In alloy NPs by the almost same procedure as the previous report ${ }^{17}$, namely, injecting $\mathrm{Fe}(\mathrm{CO})_{5}\left(n_{\mathrm{Fe}} \mathrm{mmol}\right)$ into the ODE solution $(63 \mathrm{~mL})$ containing the $\mathrm{Pd}-\mathrm{In}$ alloy $\mathrm{NPs}\left(0.50 \mathrm{mmol}_{\mathrm{Pd}}\right)$, OAm $(2.0 \mathrm{~mL})$ and $\mathrm{OA}(3.2 \mathrm{~mL})$ with stirring at $80^{\circ} \mathrm{C}$ for $1 \mathrm{~h}$ under an $\mathrm{N}_{2}$ atmosphere, and the reaction temperature was increased from $80^{\circ} \mathrm{C}$ to $180^{\circ} \mathrm{C}$ at the heating rate of $3{ }^{\circ} \mathrm{C} / \mathrm{min}$ (Table S1), where the amount of OAm was sensitive for the decomposition of $\mathrm{Fe}(\mathrm{CO})_{5}$ decomposition ${ }^{18}$. Finally, after the solution was kept at $180^{\circ} \mathrm{C}$ for $t \mathrm{~h}$ and cooled to room temperature, the $\mathrm{Pd}-\mathrm{In} @ \mathrm{FeO}_{\mathrm{y}} \mathrm{NPs}$ were collected by centrifugation with ethanol, purified twice with a $n$-hexane/ethanol (3/1 vol.\%) mixed solvent containing OAm $(0.50 \mathrm{~mL})$ and $\mathrm{OA}$ $(0.50 \mathrm{~mL})$, washed 3 times with ethanol and dried in a desiccator overnight.

Synthesis of $\mathbf{P d - P b}$ alloy NPs. After the surface ligands on Pd seeds were exchanged as the same process as Fe-Pd-In system, the OAm-protected Pd seeds were stirred with the mixture of $\mathrm{Pb}(\mathrm{OAc})_{2} \cdot 3 \mathrm{H}_{2} \mathrm{O}(0.3 \mathrm{mmol})$, distilled OAm $(36 \mathrm{~mL})$, and $\mathrm{OA}(4 \mathrm{~mL})$ at $160^{\circ} \mathrm{C}$ for $3 \mathrm{~h}$ after degassing by freeze-pump-thaw cycle (3 times). After the reaction, the organic solvent was cooled to room temperature and the $\mathrm{Pd}-\mathrm{Pb}$ alloy NPs were collected by centrifugation with ethanol and purified twice with a chloroform/ethanol (3/5 vol.\%) mixed solvent.

Synthesis of Pd-Pb@FeO $\mathbf{y}$ NPs. The $\mathrm{FeO}_{y}$ shells were covered on the $\mathrm{Pd}-\mathrm{Pb}$ alloy $\mathrm{NPs}$ by injecting $\mathrm{Fe}(\mathrm{CO})_{5}(7.4 \mathrm{mmol})$ at $80^{\circ} \mathrm{C}$ for $1 \mathrm{~h}$ under an $\mathrm{N}_{2}$ atmosphere into the mixture solution of ODE $(32 \mathrm{~mL})$, distilled-OAm $(1.0 \mathrm{~mL})$ and the $\mathrm{Pd}-\mathrm{Pb}$ alloy NPs $\left(0.25 \mathrm{mmol}_{\mathrm{Pd}}\right)$ after degassing by freeze-pump-thaw cycle ( 3 times) and increasing from $80^{\circ} \mathrm{C}$ to $140^{\circ} \mathrm{C}$ at the heating rate of $3{ }^{\circ} \mathrm{C} / \mathrm{min}$. After the solution reached at $140^{\circ} \mathrm{C}$ and was cooled to room temperature, the $\mathrm{Pd}-\mathrm{Pb} @ \mathrm{FeO} \mathrm{NPs}_{\mathrm{y}} \mathrm{Nere}$ collected by centrifugation with ethanol, purified twice with a $n$-hexane/ethanol (5/ 3 vol.\%) mixed solvent containing OAm $(0.50 \mathrm{~mL})$ and $\mathrm{OA}(0.50 \mathrm{~mL})$, washed one time with ethanol and dried in a desiccator overnight.

Reduction-diffusion process for Pd-In@FeO and Pd-Pb@FeO $\mathbf{N P s}_{\mathbf{y}}$. The $\mathrm{Pd}-\mathrm{In} @ \mathrm{FeO}_{y}-\mathrm{NPs}$ powders were heated at the rate of $10^{\circ} \mathrm{C} / \mathrm{min}$, annealed at $600^{\circ} \mathrm{C}$ or $800{ }^{\circ} \mathrm{C}$ for $3 \mathrm{~h}$ and cooled at the rate of $10^{\circ} \mathrm{C} / \mathrm{min}$ under an $\mathrm{Ar}+4 \% \mathrm{H}_{2}$ gas flowing at $0.5 \mathrm{~L} / \mathrm{min}$. The $\mathrm{Pd}-\mathrm{Pb} @ \mathrm{FeO}_{y}-\mathrm{NPs}$ powders were also annealed at $600{ }^{\circ} \mathrm{C}$ for $3 \mathrm{~h}$ via the same heating and cooling process under the same atmosphere.

Growth of $\mathbf{S i O}_{\mathbf{2}}$ shell on A1-PdIn $\mathbf{x F e O}_{\boldsymbol{y}}$ NPs. In a typical method ${ }^{28}$, the $\mathrm{SiO}_{2}$ shell was coated on $A 1-\mathrm{PdIn} \mathrm{I}_{x} @ \mathrm{FeO}_{y}$ NPs by adding TEOS $(200 \mu \mathrm{L})$ in the cyclohexane solution $(68 \mathrm{~mL})$ containing $A 1-\mathrm{PdIn}_{x} @ \mathrm{FeO}_{y} \mathrm{NPs}\left(0.25 \mathrm{mmol}_{\mathrm{Pd}}\right)$, IGEPAL@CO-520 $(9.6 \mathrm{~mL})$ and $\mathrm{NH}_{3}$ aq $(1.6 \mathrm{~mL})$ with stirring at room temperature for $16 \mathrm{~h}$. After the reaction, the A1-PdIn $@ \mathrm{FeO}_{y} @ \mathrm{SiO}_{2} \mathrm{NPs}$ were collected by centrifugation with $\mathrm{MeOH}$, purified with $\mathrm{MeOH}$ and twice with $\mathrm{EtOH}$ and dried in a desiccator overnight.

XAFS measurement. Fe K-edge, Pd K-edge, and In K-edge EXAFS measurements were performed by using the BL01B1 beamline of SPring- 8 in Japan, where the incident X-ray beam was monochromated by a $\mathrm{Si}(311)$ double crystal monochromator. The sample powder was mixed with $\mathrm{BN}$ powder and pressed into a pellet. XAFS spectra of the $L 1_{2}-(\mathrm{Fe}, \mathrm{In}) \mathrm{Pd}_{3}$ pellet were measured at $300 \mathrm{~K}$, while XAFS spectra of the $Z 3-\mathrm{Fe}\left(\mathrm{Pd}, \mathrm{In}^{d}\right)_{3}$ pellet were measured at $10 \mathrm{~K}$ in a $\mathrm{Cu}$ folder attached on a cryostat. The EXAFS analysis was carried out by using the REX2000 Ver. 2.5 program (Rigaku Co.) ${ }^{29}$. In the curve-fitting analysis of the EXAFS oscillation and Fourier transform (FT) of EXAFS, the phase shift and the backscattering amplitude function of the $\mathrm{Fe}-\mathrm{Fe}, \mathrm{Fe}-\mathrm{Pd}, \mathrm{Pd}-\mathrm{Pd}, \mathrm{Pd}-\mathrm{In}$ and $\mathrm{Fe}-\mathrm{In}$ were estimated from $\alpha$-Fe (PDF\#00-006-0696), $L 1_{0}$-FePd (PDF\#03-065-9971), Pd (PDF\#00-046-1043), B2-PdIn (PDF\#03-065-4804) and the crystal information file obtained from Rietveld refinement for $Z 3-\mathrm{Fe}\left(\mathrm{Pd}, \mathrm{In}^{d}\right)_{3}$, respectively, by using the FEFF8 program ${ }^{30}$.

TEM, HAADF-STEM and elemental-maps observations. The Pd NPs, the Pd-In alloy NPs, and the Pd-In@FeO ${ }_{y}$ NPs before and after the reduction-diffusion process were dispersed in chloroform and dropped on amorphous carbon-coated copper grids (JEOL). The TEM samples of the Fe-Pd-In ternary alloy NPs were prepared by annealing the Pd-In@FeO $\mathrm{FPs}_{y}$ on TEM grids. TEM images were recorded on a JEM1011 (JEOL) at an acceleration voltage of $100 \mathrm{kV}$. HAADFSTEM images and EDX maps were obtained by a JEM-ARM200CF at an acceleration voltage of $120 \mathrm{kV}$ for the samples prepared by dropping $\mathrm{Fe}-\mathrm{Pd}-\mathrm{In}(\mathrm{Pb})$ ternary alloy NPs on TEM grids.

Powder XRD measurement. The XRD patterns were recorded on a PANalytical X'Pert Pro MPD diffractometer with $\mathrm{Cu}$ Ka radiation $(\lambda=1.542 \AA)$ at $45 \mathrm{kV}$ and $40 \mathrm{~mA}$. Rietveld refinements were performed by using the computer program RIETAN-2000 (ref. ${ }^{31}$ ). 
EDX measurement and SEM observations. The EDX measurements were performed using EDAX APOLLO XF attached by scanning electron microscope (SEM, HITACH S-4800) at $20 \mathrm{kV}$, which detected Fe-K, Pd-L, In-L, and Pb-M peaks. The SEM images were observed at $30 \mathrm{kV}$.

$\boldsymbol{M}-\boldsymbol{H}$ hysteresis loop. The magnetization-magnetic field $(M-H)$ curves of $L 1_{2^{-}}$ $(\mathrm{Fe}, \mathrm{In}) \mathrm{Pd}_{3}$ and $\mathrm{Z3}-\mathrm{Fe}\left(\mathrm{Pd}, \mathrm{In}^{d}\right)_{3}$ structures were obtained by a VSM (TOEI VSM-5) under a magnetic field $(H)$ of -20 to $20 \mathrm{kOe}$ at room temperature $\left(\sim 25^{\circ} \mathrm{C}\right)$. To avoid rotating the grains during the magnetic measurements, the samples were fixed with eicosane (melting point of $36.7^{\circ} \mathrm{C}$ ).

Hydrogen-storage capacity. The pressure-composition isotherms were recorded on a BELSORP-HP and measured at $30^{\circ} \mathrm{C}$ and $60^{\circ} \mathrm{C}$ for the sample with the $\mathrm{Pd} / \mathrm{Fe}$ and Pd/In molar ratio of $65 / 35$ at.\% and $84 / 16$ at.\%, respectively (Supplementary Figs. 8 and 10)

First-principles calculations. We performed first-principles calculations for the $Z 3$ - and $L 1_{2}$-type $\mathrm{Fe}-\mathrm{Pd}-M$ systems within density functional theory. We used the computational code OpenMX which was based on optimized pseudopotentials and pseudo-atomic-orbital basis function ${ }^{32}$. The generalized gradient approximation of Perdew-Burke-Ernzerhof was selected for an exchange-correlation functional ${ }^{33}$. In each calculation, we replaced one $\mathrm{Fe}$ or $\mathrm{Pd}$ atom with one $M(M=\mathrm{Zn}, \mathrm{Cd}, \mathrm{Hg}$, $\mathrm{Ga}, \mathrm{In}, \mathrm{Tl}, \mathrm{Ge}, \mathrm{Sn}$, and $\mathrm{Pb}$ ) atom to determine the stability of the systems (Supplementary Tables 3-7). There are two different Wyckoff positions of Pd labeled by $4 i$ and $1 d$ that are similar to $1 b$ in $Z 3$-type $\mathrm{FePd}_{3}$. For simplicity, we noted them as $Z 3-\mathrm{Fe}_{2}\left(\mathrm{Pd}_{5}, M_{1}{ }^{i}\right)$ and $Z 3-\mathrm{Fe}_{2}\left(\mathrm{Pd}_{5}, M_{1}{ }^{d}\right)$. For the basis sets, we chose $s 2 p 2 d 2$ configurations for $\mathrm{Fe}$ and $s 2 p 2 d 2 f 1$ for $\mathrm{Pd}$ and $M$. The cut-off radius for Fe was 6.0 atomic units (a.u.) and 7.0 a.u. for Pd and In. The cut-off energy was 500 rydberg, and the $k$-point mesh was $30 \times 30 \times 16$ and $21 \times 21 \times 30$ for the $Z 3$ - and $L 1_{2}$-type $\mathrm{Fe}-\mathrm{Pd}-M$ systems, respectively. Conventional cells were chosen as $1 \times 1 \times 1$ and $\sqrt{ } 2 \times \sqrt{ } 2 \times 1$ for the $Z 3$ - and $L 1_{2}$-type Fe-Pd- $M$ systems, respectively. These conventional cells had the same number and kinds of atoms in a unit cell, which allowed us to compare the energy difference between these systems easily. Obtained calculation results were at $0 \mathrm{~K}$ and we did not consider the reaction paths of how the In-doped $\mathrm{FePd}_{3}$ structure was fabricated because of the limitation of the firstprinciples calculations. The formation energies of $L 1_{2}-\left(\mathrm{Fe}_{2-x}, \mathrm{In}_{x}\right) \mathrm{Pd}_{6}$ and $Z 3-\mathrm{Fe}_{2}\left(\mathrm{Pd}_{6-x} \mathrm{In}_{x}{ }^{d}\right)\left(E_{L 12}\right.$ and $E_{Z 3}$, respectively) were estimated by comparing $E_{L 12}$ and $E_{Z 3}$ under the same number and kinds of atoms as follows $(0<x<1)$;

$$
E_{L 12}=x \times E\left[L 1_{2}-\left(\mathrm{Fe}_{1}, \mathrm{In}_{1}\right) \mathrm{Pd}_{6}\right]+(1-x) \times E\left[L 1_{2}-\mathrm{Fe}_{2} \mathrm{Pd}_{6}\right]+x \times \mu[\mathrm{Fe}]
$$

and

$$
E_{Z 3}=x \times E\left[Z 3-\mathrm{Fe}_{2}\left(\mathrm{Pd}_{5}, \operatorname{In}_{1}{ }^{d}\right)\right]+(1-x) \times E\left[Z 3-\mathrm{Fe}_{2} \mathrm{Pd}_{6}\right]+x \times \mu[\mathrm{Pd}]
$$

where $E$ [phase] is the $E_{\text {form }}$ of each phase. Furthermore, in order to analyse the magnetic anisotropy of $Z 3$ - and $L 1_{2}$-type Fe-Pd-In in Fig. 4 , we compared the total energies obtained by non-collinear calculations in which spin directions on each atom were fixed within $0<\theta\left({ }^{\circ}\right)<90$ and $0<\varphi\left({ }^{\circ}\right)<45$ (i.e., from [001] to [100] at $\varphi=0$ and from [100] to [110] at $\theta=0$ ). Conventional cells in these non-collinear calculations were expanded to $2 \times 2 \times 1$ and $2 \times 2 \times 2$ for $Z 3-\mathrm{Fe}_{8}\left(\mathrm{Pd}_{20}, \mathrm{In}_{4}{ }^{d}\right)$ and $L 1_{2}-\left(\mathrm{Fe}_{7}, \mathrm{In}_{1}\right) \mathrm{Pd}_{24}$ systems, respectively (Supplementary Table 8 ).

\section{Data availability}

All data supporting the findings of this study are available from the corresponding author on request.

Received: 12 February 2021; Accepted: 28 January 2022; Published online: 24 February 2022

\section{References}

1. Hoffmann, R. Solids and Surfaces: A Chemist's View of Bonding in Extended Structures (VCH Publisher, 1988).

2. Kusada, K. et al. Discovery of face-centered-cubic ruthenium nanoparticles: facile size-controlled synthesis using the chemical reduction method. J. Am. Chem. Soc. 135, 5493-5496 (2013).

3. Watanabe, S., Komine, T., Kai, T. \& Shiiki, K. First-principle band calculation of ruthenium for various phases. J. Magn. Magn. Mater. 220, 277-284 (2000).

4. Quarterman, P. et al. Demonstration of $\mathrm{Ru}$ as the 4 th ferromagnetic element at room temperature. Nat. Commun. 9, 2058 (2018).

5. Fan, Z. \& Zhang, H. Crystal phase-controlled synthesis, properties and applications of noble metal nanomaterials. Chem. Soc. Rev. 45, 63-82 (2016).

6. Barabash, S. V., Chepulskii, R. V., Blum, V. \& Zunger, A. First-principles determination of low-temperature order and ground states of $\mathrm{Fe}-\mathrm{Ni}, \mathrm{Fe}-\mathrm{Pd}$, and Fe-Pt. Phys. Rev. B 80, 220201 (2009).
7. Chepulskii, R. V., Barabash, S. V. \& Zunger, A. Ab initio theory of phase stability and structural selectivity in Fe-Pd alloys. Phys. Rev. B 85, 144201 (2012).

8. Massalski, T. B., Okamoto, H., Subramanian, P. R. \& Kacprzak, L. Binary Alloy Phase Diagrams (ASM International, ed. 2, 1990).

9. Kobayashi, H., Kusada, K. \& Kitagawa, H. Creation of novel solid-solution alloy nanoparticles on the basis of density-of-states engineering by interelement fusion. Acc. Chem. Res. 48, 1551-1559 (2015).

10. Clarke, $\mathrm{S}$. M. et al. Discovery of a superconducting $\mathrm{Cu}-\mathrm{Bi}$ intermetallic compound by high-pressure synthesis. Angew. Chem. Int. Ed. 15, 13446-13449 (2016).

11. Sato, H. et al. Fabrication of L11 type Co-Pt ordered alloy films by sputter deposition. J. Appl. Phys. 103, 07E114 (2008).

12. Goto, S. et al. Synthesis of single-phase L10-FeNi magnet powder by nitrogen insertion and topotactic extraction. Sci. Rep. 7, 13216 (2017).

13. Vojvodic, A. et al. Exploring the limits: A low-pressure, low-temperature Haber-Bosch process. Chem. Phys. Lett. 598, 109-112 (2014).

14. Ishikawa, H. et al. Pd-In-Fe shape memory alloy. Appl. Phys. Lett. 90, 261906 (2007).

15. Shen, Q., Zhao, D., Sun, W., Wei, Z. \& Liu, J. Microstructure, martensitic transformation and elastocaloric effect in Pd-In-Fe polycrystalline shape memory alloys. Intermetallics 100, 27-31 (2018).

16. Vokoun, D., Hu, C. T., Lo, Y. H., Lančok, A. \& Heczko, O. Transformation properties of $\mathrm{Fe}_{70}-\mathrm{Pd}_{30} \mathrm{XInX}$ shape memory melt-spun ribbons. Mater. Today.: Proc. 2S, S845-S848 (2015).

17. Matsumoto, K. et al. Formation of strong L10-FePd/a-Fe nanocomposite magnets by visualizing efficient exchange coupling. Nanoscale Adv. 1, 2598-2605 (2019).

18. Kura, H., Takahashi, M. \& Ogawa, T. Synthesis of monodisperse iron nanoparticles with a high saturation magnetization using an $\mathrm{Fe}(\mathrm{CO})$ x-oleylamine reacted precursor. J. Phys. Chem. C. 114, 5835-5838 (2010).

19. Lavrentiev, M. Y., Wróbel, J. S., Nguyen-Manh, D. \& Dudarev, S. L. Magnetic and thermodynamic properties of face-centered cubic Fe-Ni alloys. Phys. Chem. Chem. Phys. 16, 16049-16059 (2014).

20. Kubaschewski, O. Iron-Binary Phase Diagrams (Springer, 1982).

21. Klemmer, T., Hoydick, D., Okumura, H., Zhang, B. \& Soffa, W. A. Magnetic hardening and coercivity mechanisms in L10 ordered FePd ferromagnets. Scr. Met. Mater. 33, 1793-1805 (1995).

22. Liu, S. H. et al. Crystallographic structure and magnetic properties of polycrystalline FePd thin films on glass substrate. Appl. Phys. A 119, 623 (2015).

23. Pandey, T. \& Parker, D. S. Magnetic properties and magnetocrystalline anisotropy of $\mathrm{Nd}_{2} \mathrm{Fe}_{17}, \mathrm{Nd}_{2} \mathrm{Fe}_{17} \mathrm{X}_{3}$, and related compounds. Sci. Rep. 8, 3601 (2018).

24. Kobayashi, H., Yamauchi, M., Ikeda, R. \& Kitagawa, H. Atomic-level Pd-Au alloying and controllable hydrogen-absorption properties in size-controlled nanoparticles synthesized by hydrogen reduction. Chem. Commun. 4806-4808 (2009).

25. Dekura, S., Kobayashi, H., Kusada, K. \& Kitagawa, H. Hydrogen in palladium and storage properties of related nanomaterials: size, shape, alloying, and metal-organic framework coating effects. Chem. Phys. Chem. 20, 1158-1176 (2019).

26. Hart, G. L. W., Curtarolo, S., Massalski, T. B. \& Levy, O. Comprehensive search for new phases and compounds in binary alloy systems based on platinum-group metals, using a computational first-principles approach. Phys. Rev. X 3, 041035 (2013)

27. Seko, A., Shitara, K. \& Tanaka, I. Efficient determination of alloy ground-state structures. Phys. Rev. B 90, 174104 (2014).

28. Bae, D. S., Han, K. S. \& Adair, J. H. Synthesis and microstructure of $\mathrm{Pd} / \mathrm{SiO}_{2}$ nanosized particles by reverse micelle and sol-gel processing. J. Mater. Chem. 12, 3117 (2002)

29. Yamazoe, S. et al. Hierarchy of bond stiffnesses within icosahedral-based gold clusters protected by thiolates. Nat. Commun. 7, 10414 (2016).

30. Ankudinov, A. L., Ravel, B., Rehr, J. J. \& Conradson, S. D. Real-space multiplescattering calculation and interpretation of $\mathrm{x}$-ray-absorption near-edge structure. Phys. Rev. B 58, 7565-7576 (1998).

31. Izumi, F. \& Ikeda, T. A Rietveld-analysis programm RIETAN-98 and its applications to zeolites. Mater. Sci. Forum 321-324, 198-205 (2000).

32. Ozaki, T. Variationally optimized atomic orbitals for large-scale electronic structures. Phys. Rev. B 67, 155108 (2003).

33. Perdew, J. P., Burke, K. \& Wang, Y. Generalized gradient approximation made simple. Phys. Rev. Lett. 77, 3865-3868 (1996).

\section{Acknowledgements}

XAFS measurements were performed at the BL01B1 of SPring- 8 with the approval of the Japan Synchrotron Radiation Research Institute (JASRI) (Proposal No. 2018A0910 (S.Y.) 2018 B1119 (R.T.) and 2018B1422 (S.Y.)) after the experiment of the anomalous XRD 
measurement at the BL13XU of SPring-8 (Proposal No. 2018A1666 (K.M.)), which gave the opportunity for the XAFS measurements. EDX elemental maps at atomic resolution were obtained by Advanced Characterization Platform of the Nanotechnology Platform Japan sponsored by the Ministry of Education, Culture, Sports, Science and Technology (MEXT), Japan (Proposal No. JPMXP09A18KU0274 (Y.H.), JPMXP09A20KU0357 (K.M.)). The first-principles calculations were partly carried out by using supercomputers at ISSP, The University of Tokyo. This work was supported by the MEXT/Japan Society for the Promotion of Science (JSPS) KAKENHI for Scientific Research (S) (Grant No. JP19H05634 (T. Teranishi)), Scientific Research (B) (Grant Nos. JP16H03826 (T. Teranishi) and JP18H01953 (R.S.)), Scientific Research (C) (Grant No. JP21K04630 (Y.T.)), Challenging Research (Exploratory) (Grant Nos. JP19K22231 (T. Teranishi) and JP17K19178 (R.S.)) and for JSPS Research Fellowship (Grant No. JP18J15062 (K.M.)). This work was partially supported by the International Collaborative Research Program of Institute for Chemical Research, Kyoto University (grant \# 2020-17).

\section{Author contributions}

K.M., R.S., and T.Te. conceived the study. K.M. and R.S. designed the synthesis scheme. K.M. performed the synthesis, the characterizations and the magnetic measurements. Y.T. performed the first-principles calculations. K.M., R.T., and S.Y. measured and analysed the XAFS spectra. M.Y. and Y.I. measured the pressure-composition isotherms for hydrogen gas. Y.H., M.K., T.To., M.A., M.H., and H.K. observed the EDX elemental maps and HAADF-STEM. K.M., R.S., Y.T., and T.Te. co-wrote the manuscript. Al authors discussed the results and commented on the manuscript.

\section{Competing interests}

The authors declare no competing interests.

\section{Additional information}

Supplementary information The online version contains supplementary material available at https://doi.org/10.1038/s41467-022-28710-0.

Correspondence and requests for materials should be addressed to Toshiharu Teranishi.

Peer review information Nature Communications thanks Jiajia Han, Florent Calvo, and the other, anonymous, reviewer for their contribution to the peer review of this work.

Reprints and permission information is available at http://www.nature.com/reprints

Publisher's note Springer Nature remains neutral with regard to jurisdictional claims in published maps and institutional affiliations.

(c) Open Access This article is licensed under a Creative Commons Attribution 4.0 International License, which permits use, sharing, adaptation, distribution and reproduction in any medium or format, as long as you give appropriate credit to the original author(s) and the source, provide a link to the Creative Commons license, and indicate if changes were made. The images or other third party material in this article are included in the article's Creative Commons license, unless indicated otherwise in a credit line to the material. If material is not included in the article's Creative Commons license and your intended use is not permitted by statutory regulation or exceeds the permitted use, you will need to obtain permission directly from the copyright holder. To view a copy of this license, visit http://creativecommons.org/ licenses/by/4.0/.

(C) The Author(s) 2022 